\title{
Evaluation of Two Wild Castor (Ricinus Communis L.) Accessions for Cadmium Tolerance in Relation to Antioxidant Systems and Lipid Peroxidation
}

\author{
Akwasi Yeboah \\ Guangdong Ocean University \\ Jiannong Lu \\ Guangdong Ocean University \\ Shuailei Gu \\ Guangdong Ocean University \\ Liu Haiyan \\ Guangdong Ocean University \\ Yuzhen Shi \\ Guangdong Ocean University \\ Hanna Amoanimaa-Dede \\ Guangdong Ocean University \\ Kwadwo Gyapong Agyenim-Boateng \\ Chinese Academy of Agricultural Sciences \\ Joseph Payne \\ University for Development Studies \\ Xuegui Yin ( $\nabla$ yinxuegui261@gmail.com ) \\ Guangdong Ocean University
}

\section{Research Article}

Keywords: antioxidants, cadmium, reactive oxygen species, tolerance index, oxidative stress.

Posted Date: May 27th, 2021

DOI: https://doi.org/10.21203/rs.3.rs-167950/v1

License: (c) (i) This work is licensed under a Creative Commons Attribution 4.0 International License.

Read Full License 


\section{Abstract}

The present study was conducted to assess the effect of toxicity of cadmium (Cd) on growth, tolerance index (TI), antioxidant activities, and malondialdehyde (MDA) content in two contrasting wild castor accessions (16-024 and S2-4) via hydroponic experiment ( 0 and $100 \mathrm{mg} / \mathrm{L} \mathrm{Cd}$ ). The results showed that $\mathrm{Cd}$ significantly reduced the growth rate, seedling height, root length, and shoot length of the castor accessions compared to control, with the Cd effect being more severe in S2-4 than in 16-024. In addition, biomass response including the root and shoot fresh weight and root dry weight decreased in both accessions compared to control. Shoot dry weight of $16-024$ increased $(p>0.05)$ by $2.04 \%$ compared to S2-4 which declined by $21.07 \%$, suggesting a minimal effect of $C d$ and a level of tolerance in 16-024. Analysis of TI on all the growth parameters and biomass content revealed that accession 16-024 was highly tolerant to $\mathrm{Cd}$ stress than S2-4. The results further revealed that the expression of the antioxidant enzymes viz., superoxide dismutase (SOD), catalase (CAT), non-enzymatic antioxidant; glutathione, and MDA content, were influenced by genotype. S2-4 exhibited a higher antioxidant activity (SOD, CAT) and lipid peroxidation activity than 16-024, indicative of oxidative damage from Cd stress.

\section{Introduction}

Cadmium (Cd) is one of the highly toxic heavy metals with detrimental effects to agricultural soil, plants, and water bodies because it is highly soluble in water and readily absorbed into plant tissues (Shahid et al. 2016). Cd as a non-essential heavy metal is primarily released into environments mostly by anthropogenic or natural activities (Shahid et al. 2016). The absorption of Cd by plants negatively affects their growth, biomass, root length, shoot length, and causes leaf chlorosis and root darkening (de Souza Costa et al. 2012); however, these effects vary from plant species. Once Cd is absorbed by the plant, it enters into the human body via the food chain thereby endangering human health (Sharma et al. 2015). Diseases such as renal tubular damage and pulmonary emphysema in humans have been associated with the consumption of Cd contaminated foods (Sharma et al. 2015; Tinkov et al. 2018).

$\mathrm{Cd}$ is a non-redox active metal that does not participate in Fenton-type reactions, but it induces oxidative stress by the production of reactive oxygen species (ROS) such as superoxide anions $\left(\mathrm{O}_{2}{ }^{\bullet-}\right)$, hydroxyl radical $\left(\mathrm{OH}^{\bullet}\right)$, and hydrogen peroxide $\left(\mathrm{H}_{2} \mathrm{O}_{2}\right)$ (Bauddh et al. 2016; Shah et al. 2001). These ROS react with lipids, nucleic acids, and proteins and cause membrane damage, enzyme inhibition, and lipid peroxidation, thus affecting the viability of cells (Gill et al. 2011). Malondialdehyde (MDA), a product of the decomposition of lipid peroxidation is induced by oxidative stress (Kiran and Prasad 2017). Previous studies have shown that increasing Cd stress increases MDA content and is highly related to the increase in ROS levels (Bauddh and Singh 2012; Shah et al. 2001; Yu et al. 2013). Therefore, MDA is regarded as the major bio-indicator of oxidative damage in plants (Kiran and Prasad 2017). To combat the toxic effects of ROS and oxidative stress induced by Cd, plants activate ROS-detoxifying antioxidant defense mechanisms to maintain a balance between ROS production and decomposition (Gill et al. 2011; Yeboah et al. 2020b). The antioxidant defense systems consisting of enzymes such as superoxide dismutase 
(SOD) and catalase (CAT) and non-enzymatic antioxidant such as glutathione (GSH) help scavenge ROS to maintain the cellular redox homeostasis (Shah et al. 2001; Yeboah et al. 2020b). SOD acts as a first line of cellular defense and dismutase $\mathrm{O}_{2}{ }^{-\boldsymbol{}}$ to $\mathrm{O}_{2}$ and $\mathrm{H}_{2} \mathrm{O}_{2}$. CAT regulates the accumulation of $\mathrm{H}_{2} \mathrm{O}_{2}$ levels which later catalyzes $\mathrm{H}_{2} \mathrm{O}$ and $\mathrm{O}_{2}$ (Bauddh et al. 2016; Yu et al. 2013). $\mathrm{GSH}$ is a water-soluble antioxidant that directly combines with cellular electrophiles for antioxidant production or detoxification (Li et al. 2013; Shah et al. 2001). It also enhances plant responses to metal stress as a precursor of phytochelatins (PCs) and helps scavenge excess $\mathrm{H}_{2} \mathrm{O}_{2}$ (Zhang et al. 2014). Owing to the beneficial role of antioxidant systems in response to metal stress, several studies have been carried out on the tolerance mechanisms in diverse plant species (particularly edible plant species) under different Cd concentration and stresses (Dandan et al. 2011; Shah et al. 2001; Xu et al. 2014; Yu et al. 2013; Zeng et al. 2017) to better understand $\mathrm{Cd}$ tolerance mechanisms in order to and breed for tolerant accessions that can subsequently be used for phytoremediation of $\mathrm{Cd}$ in $\mathrm{Cd}$-contaminated environments. However, information about the tolerance mechanisms of non-edible plant species such as castor to metal stress is meager.

Castor (Ricinus communis L.), an industrial non-edible oilseed crop belonging to the family Euphorbiaceae, is widely grown in the tropics and subtropical parts of the world. The oil in the castor oilseed is the sole oil that contains a high percentage of ricinoleic acid, making it useful for a wide spectrum of applications (Anjani 2014; Yeboah et al. 2020c). It is commercially used for medicine, agriculture, cosmetics, among others (Anjani 2014). Aside these, several studies have proposed its potential use as a phytoremediator (Yeboah et al. 2020a) owing to its high tolerance to heavy metal stress such as copper (Wang et al. 2016), lead (Pal et al. 2013; Prasad 2017), zinc (Wang et al. 2016), and Cd (Huang et al. 2011; Shi and Cai 2009; Ye et al. 2018; Zhang et al. 2014). From the limited studies on Cd stress, most reported that castor plant possess potential defense mechanisms, specifically the antioxidant defense systems (Bauddh et al. 2016; Bauddh and Singh 2012; Zhang et al. 2014). Nevertheless, a number of the studies were conducted in soil/field other than hydroponic culture (Bauddh et al. 2016; Bauddh and Singh 2012). Hydroponic experiment is more advantageous over soil/field experiment owing to the minimal interaction of the hydroponic medium with the experiment unlike in the soil/field where the soil and the organic matter may influence the experiment either by desorption or absorption (for metal exposure experiment) in the soil solution (de Souza Costa et al. 2012). Although hydroponic experimental conditions cannot be directly extrapolated to real field conditions, they are important as a means to determine the plant's ability to tolerate relatively high metal concentrations maintaining fast growth rates as well as high biomass production (de Souza Costa et al. 2012).

In addition, most of the antioxidant studies in castor under Cd stress were determined at the matured stage with limited studies at the seedling stage (Bauddh et al. 2016). In reality, after sowing, the castor plant undergoes three stages, that is; the seedling stage, growth stage, and maturity stage. The matured castor plant may withstand Cd stress to some extent whereas the seedling may not (He et al. 2020). Thus, it is imperative to evaluate the antioxidant defense systems at the seedling stage to better 
understand the tolerance mechanisms employed by castor against $\mathrm{Cd}$ toxicity and to ensure the successful selection and breeding of castor accessions with superior tolerance to $\mathrm{Cd}$ toxicity.

Generally, the wild castor plant has strong adaptability and resistance to various abiotic and biotic stress compared to other materials (hybrids and cultivars) which makes them more useful for breeding purposes and remediation of contaminated soils (Kang et al. 2015). However, different wild castor accessions have different growth performance rate, adaptability, and tolerance to various abiotic and biotic stress (Kang et al. 2015). Therefore, it is essential to ascertain the tolerance level of every accession discovered. For instance, Kang et al. (2015) reported that wild castor accessions could grow and tolerate increasing concentrations of $\mathrm{CuSO}_{4}(100 \mathrm{mg} / \mathrm{L})$ in hydroponic culture for 20 days.

In this study, two wild castor accessions (16-024 and S2-4) obtained from the breeding unit of the department of crop genetics and breeding of Guangdong Ocean University were selected on the basis of their growth performance and responses to different $\mathrm{Cd}$ concentration based on our previous study (Unpublished data). This study was conducted to evaluate the tolerance mechanisms and level of oxidative damage in the two wild castor accessions exposed to $\mathrm{Cd}$ stress in a hydroponic culture. This was achieved by evaluating the growth, tolerance index (TI), and tolerance mechanisms in the wild accessions under $\mathrm{Cd}$ stress. Our findings would be helpful to understand $\mathrm{Cd}$ mechanisms and detoxification in this plant. Also, this would be valuable for castor breeding efforts and phytoremediation in general.

\section{Materials And Methods}

Plant material and growth condition

Seeds of two wild castor accessions 16-024 and S2-4 were provided by the Department of Crop Breeding and Genetics, Guangdong Ocean University, Zhanjiang, China. Castor seeds from each accession were surface sterilized with $2 \%$ sodium hypochlorite solution for about $12 \mathrm{~min}$ and imbibed in distilled water for $24 \mathrm{hrs}$ at $28^{\circ} \mathrm{C}$ for uniform germination. The seeds were initially grown in plastic seedling trays containing vermiculite for 15 days. Uniform-sized seedlings from each accession were washed and transferred to $6 \mathrm{~L}$ plastic boxes containing 6 holes per box. Each box was filled with 5 - $\mathrm{L}$ of half-strength Hoagland's solution with the following composition: $5 \mu \mathrm{mol} / \mathrm{L}$ EDTAFeNa, $0.05 \mathrm{mmol} / \mathrm{L} \mathrm{NH} 4 \mathrm{NO} 3,0.15$ $\mu \mathrm{mol} / \mathrm{L}$ CuSO4, $1.9 \mu \mathrm{mol} / \mathrm{L}$ ZnSO4, $2.25 \mu \mathrm{mol} / \mathrm{L} \mathrm{MnCl} 2,25 \mu \mathrm{mol} / \mathrm{L} \mathrm{H3BO3,} 0.5 \mathrm{mmol} / \mathrm{L} \mathrm{MgSO} 4,0.5$

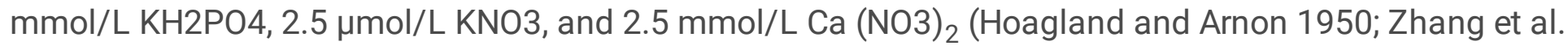
2014) and left for seven days for acclimatization. After acclimatization, six seedlings were set as control and six seedlings for $\mathrm{Cd}$ treatment for each accession with one hole per plant; three seedlings were used for determination of growth parameters and biochemical analyses. Cadmium Chloride $(\mathrm{CdCl} \cdot 2.5 \mathrm{H} 2 \mathrm{O}$, CAS: 7790-78-5) obtained from a certified company (Shanghai Macklin Biochemical Company) was used for providing Cd pollution. 22-day old castor seedlings were exposed to Cd at 0 (control) and $100 \mathrm{mg} / \mathrm{L}$ for 5 days. We chose this concentration and number of days after conducting a trial experiment (exposure for seven days) (Unpublished data). Castor plant exposure to Cd concentration below 100 
$\mathrm{mg} / \mathrm{L}$ did not affect growth parameters significantly, however, Cd toxicity was observed on the root (dark root) by the fourth day, whiles those exposed to $100 \mathrm{mg} / \mathrm{L}$ showed a sharp decrease in growth. All the experiments were arranged in a completely randomized design and nutrient solutions were replaced every three days. The $\mathrm{pH}$ was maintained at $6.0( \pm 0.1)$ by the addition of either $0.1 \mathrm{~mol} / \mathrm{L} \mathrm{NaOH}$ or $\mathrm{HCl}$. The whole experiment took place in a controlled-climate room under strictly regulated environmental conditions at Zhanjiang Lanying Agricultural Technology. Relative humidity was maintained between 65 $\%$ and $75 \%$, the light/dark cycle was $16-8 \mathrm{hr}$ with a respective $25-27^{\circ} \mathrm{C}$ temperature periodicity, and light intensity was kept at a constant $300 \mu \mathrm{mol} \mathrm{m} \mathrm{m}^{-2} \mathrm{~s}^{-1}$ during the daytime.

Plant growth parameter analysis and tolerance index

Growth characteristics such as seedling height, root length, shoot length, and biomass production of both fresh weight (fwt) and dry weight (dwt) of root and shoot were measured after 5 days of Cd treatment. The seedling height, root length, and shoot length were measured using a meter scale. The fwt of biomass was measured using an electronic balance and these same plants were later dried in an oven for $72 \mathrm{hr}$ at $70^{\circ} \mathrm{C}$ to achieve a constant weight and were recorded as dry wt. In response to Cd stress, indices were calculated according to the following equations (Shi and Cai 2009; Wu et al. 2016).

Growth performance $=$ [Growth parameters under Cd stress (GPcd) - Growth parameters under control (GPck)] / [GPck] × $100 \%$ where GPcd and GPck denote root length, shoot length, and root and shoot biomass under $\mathrm{Cd}$ stress and $\mathrm{CK}$ (control), respectively.

The TI was determined based on all the growth parameters and calculated as the following (Zacchini et al. 2009): $\mathrm{TI}=$ [Growth parameters Cd] / [Growth parameters control] $\times 100 \%$.

Determination of antioxidant enzymes activities

Prior to the determination of antioxidant activities, the plant leaves under stress and those without stress were harvested and immediately stored in liquid nitrogen to maintain the activity of their enzymes. About $100 \mathrm{mg}$ fresh weight of leaf were homogenized with phosphate buffer solution ( $\mathrm{pH} 7.4)$ using TissueLyser II machine for $15 \mathrm{~min}$ and then centrifuged at $12,000 \mathrm{x} \mathrm{g}$ for $20 \mathrm{~min}$ at $4^{\circ} \mathrm{C}$. The supernatants were stored at $4^{\circ} \mathrm{C}$ and further used for the analysis of antioxidants enzyme activities including SOD and CAT. The SOD activity was based on the inhibition of the photochemical reduction of nitro blue tetrazolium (NBT) under $\mathrm{H}_{2} \mathrm{O}_{2}$ and light following the method of Beauchamp and Fridovich (1971). The reaction was initiated by illumination after riboflavin addition and terminated after 15 min incubation in dark and the absorbance was measured at $560 \mathrm{~nm}$. One SOD activity was defined as the amount of protein required to inhibit $50 \%$ initial reduction of NBT under environmental conditions and was expressed as $\mathrm{U} / \mathrm{g}$ fresh weight ( $\mathrm{fw}$ ).

CAT activity was analyzed by the consumption of $\mathrm{H}_{2} \mathrm{O}_{2}$ at $240 \mathrm{~nm}$ as described by Aebi (1984). Reduction of 0.01 units at A240 per min was considered as one unit of enzyme activity (U), and CAT activity was expressed as $\mathrm{U} / \mathrm{g} \mathrm{fw}$. 
Approximately $100 \mathrm{mg}$ fresh leaf were homogenized with phosphate buffer solution $(\mathrm{pH}=7.4)$ using TissueLyser II machine and then centrifuged at $12,000 \times \mathrm{g}$ for $20 \mathrm{~min}$ at $4^{\circ} \mathrm{C}$ and the supernatants were collected. The enzyme extraction and analysis were conducted following the method described by Knörzer et al. (1996) and Eyer and Podhradsky (1986).

Determination of lipid peroxidation

The level of lipid peroxidation in the leaves was measured in terms of MDA content determined by estimating thiobarbituric acid (TBA) reactive substances as described by Dhindsa et al. (1981). Briefly, $100 \mathrm{mg}$ leaf samples were homogenized in $10 \mathrm{ml}$ of trichloroacetic acid (TCA, $10 \%$ ) using the TissueLyser II machine. The homogenate was centrifuged at 10,000 x g for $10 \mathrm{~min}$, after which the supernatants were collected. A mixture of $1 \mathrm{ml}$ of supernatant and $2 \mathrm{~mL}$ of $0.5 \% 2$ - TBA in $10 \%$ TCA was heated at $95^{\circ} \mathrm{C}$ for $15 \mathrm{~min}$ and then quickly cooled in an ice bath. After centrifuging at $10,000 \times \mathrm{g}$ for 10 min the absorbance of the supernatant was measured at $532 \mathrm{~nm}$ and corrected for non-specific turbidity by subtracting the absorbance of the same at $600 \mathrm{~nm}$. The blank was $0.5 \%$ TBA in $10 \%$ TCA. The concentration of MDA $\left(\mathrm{C}_{\mathrm{MDA}}\right)$ in the reaction solution was calculated using the extinction coefficient (155 $\left.\mathrm{mM}^{-1} \mathrm{~cm}^{-1}\right)$.

Antioxidant enzymes, GSH, and MDA were all analyzed using an ultraviolet-visible spectrophotometer (UV-1100, Metash, China) at the Department of Crop Breeding and Genetics laboratory, Guangdong Ocean University, China.

Statistical Analysis

All data $(n=3)$ were analyzed using SPSS version 22.0 (SPSS, Inc., Chicago, IL). Data were subjected to paired-samples $t$-test at a confidence interval of $95 \%$ to compare the significant differences between the control and Cd stress plants as well as between accessions. Graphical work was done with GraphPadPrism version 8.0 (GraphPad Software, San Diego California USA, www.graphpad.com).

\section{Results And Discussion}

Plant growth parameter (growth rate, seedling length, root length, and shoot length)

Increased industrialization and urbanization have markedly contributed to soil contamination by $\mathrm{Cd}$ which impairs plant growth and development, as well as reduction of plant metabolism (de Souza Costa et al. 2012). It is established that plant accessions vary in their tolerance to Cd toxicity. Therefore in this study, two contrasting wild castor accessions were used to investigate the growth, biomass production, $\mathrm{TI}$, antioxidant system, and lipid peroxidation in castor under $\mathrm{Cd}$ stress for 5 days. The results showed a wide variation between the accessions with respect to all the parameters investigated (Table 1, Figs. 1 and 2). The growth rate of the castor accessions were inhibited upon $\mathrm{Cd}$ treatment in the growth medium 
compared to their control groups and symptoms of $\mathrm{Cd}$ toxicity such as root darkening occurred. The inhibitory effect of Cd was more severe in S2-4 compared to 16-024. Mostly low Cd exposure (below 5 $\mu \mathrm{M}$ ) results in low or no phytotoxicity depending on the plant species (Yang et al. 2018). However high Cd concentration, especially above $100 \mathrm{mg} / \mathrm{kg}$ has been associated with massive reduction in plant growth accompanied with high phytotoxicity such as leaf spot, chlorosis, and necrosis (Shi and Cai 2009; Yang et al. 2018). Hence, our results of Cd toxicity and reduction in growth rate observed in the castor accessions compared to the control may also be due to the high $\mathrm{Cd}$ concentration which restricted the intake of essential nutrients in the growth medium thereby disrupting the plant metabolism. These findings are in consonance with previous studies reported in kenaf (Li et al. 2013), maize (Xu et al. 2014), castor (Hazama et al. 2015), sugarcane (Zeng et al. 2017), and switchgrass (Guo et al. 2019). This present study confirms that high $\mathrm{Cd}$ concentration causes cytotoxicity and reduction in plant growth.

The seedling height, root length, and shoot length of the castor accessions in Cd stress decreased compared to their controls (Table 1). Cd stress decreased seedling height of plants by $25.8 \%$ in 16-024 and $43.8 \%$ in S2-4 with respect to their control group. Compared to the control, the decline in root and shoot length of 16-024 were $27.7 \%$ and $24.3 \%$, respectively; the decreased values of root and shoot length of S2-4 were $50.0 \%$ and $36.6 \%$, suggesting a higher decrease in S2-4 than 16-024, respectively. A possible explanation for the higher decrease in height, root and shoot length in S2-4 may be due to its higher sensitivity to $\mathrm{Cd}$ stress. Also, a similar study has reported a wide variation between two kenaf accessions when exposed to $20 \mu / \mathrm{mol} \mathrm{Cd}$ in the growth medium. It was found that the kenaf Cd-sensitive cultivar 'ZM412' recorded a higher decrease in root and shoot length compared to the Cd-tolerant cultivar 'Fuhong 991' (Li et al. 2013). Yang et al. (2018) reported a significant reduction in length which varied among seven genotypic Salix species upon Cd exposure.

\section{Biomass response under Cd stress}

Biomass reduction is a general response of higher plants and an important indicator to evaluate metal toxicity in plants. Previous studies have reported a decline in root and shoot biomass due to Cd stress (de Souza Costa et al. 2012; Shi and Cai 2009; Xu et al. 2014; Zeng et al. 2017). Table 1 shows that the fwt and dwt of biomass of the castor accession under Cd stress decreased compared to their control groups. Suppression of fwt of root and shoot biomass in 16-024 were $47.1 \%$ and $59.2 \%$, respectively, and that of S2-4 were $64.8 \%$ and $65.3 \%$, compared to their control groups. Compared to control group, the root and shoot dwt of $16-024$ significantly decreased $(p<0.05)$ and insignificantly increased $(p>0.05)$, respectively, by $11.5 \%$ and $2 \%$. The insignificant increase in shoot dwt of $16-024$ suggests certain level of tolerance in this accession to Cd stress. Conversely, S2-4 had both root and shoot dwt decreased ( $p$ > 0.05 ) by $36.0 \%$ and $21.7 \%$, respectively compared to control groups (Table 1 ). The biomass variation between the two castor accessions in response to $\mathrm{Cd}$ stress could be attributed to the differences in their genetic makeup. 16-024 was relatively tolerant to $\mathrm{Cd}$ stress and exhibited a minimal reduction in all growth parameters and biomass production compared to S2-4 in the growth medium. Also, it was observed that, except shoot dwt, all the other biomass parameters (Table 1) tested decreased, and hence this proposes that $\mathrm{Cd}$ toxicity has varied effect among the plant parts. Nevertheless, to better understand 
and distinguish the tolerance ability between the two castor accessions, the $\mathrm{TI}$ and biochemical mechanisms were further investigated in this study.

Table 1

Growth and biomass of two castor accessions under control and Cd treatment

\begin{tabular}{|c|c|c|c|c|c|c|c|}
\hline \multirow{2}{*}{$\begin{array}{l}\text { Cd } \\
\text { treatment } \\
\text { (mg/L) }\end{array}$} & \multirow[t]{2}{*}{$\begin{array}{l}\text { Seedling } \\
\text { height (cm) }\end{array}$} & \multirow{2}{*}{$\begin{array}{l}\text { Root } \\
\text { length } \\
\text { (cm) }\end{array}$} & \multirow{2}{*}{$\begin{array}{l}\text { Shoot } \\
\text { length } \\
\text { (cm) }\end{array}$} & \multicolumn{2}{|c|}{$\begin{array}{l}\text { Fresh weight of } \\
\text { biomass (g/plant) }\end{array}$} & \multicolumn{2}{|c|}{$\begin{array}{l}\text { Dry weight of } \\
\text { biomass (g/plant) }\end{array}$} \\
\hline & & & & Root & Shoot & Root & Shoot \\
\hline \multicolumn{8}{|l|}{$16-024$} \\
\hline \multirow[t]{2}{*}{0} & \multirow[t]{2}{*}{$36.2 \pm 2.13$} & \multirow{2}{*}{$\begin{array}{l}16.0 \pm \\
1.00\end{array}$} & $20.2 \pm$ & $3.18 \pm$ & \multirow{2}{*}{$\begin{array}{l}8.61 \pm \\
0.15\end{array}$} & $0.09 \pm$ & $0.15 \pm$ \\
\hline & & & 1.13 & 0.12 & & 0.01 & 0.01 \\
\hline \multirow[t]{2}{*}{100} & \multirow[t]{2}{*}{$26.8 \pm 1.23^{\star}$} & \multirow{2}{*}{$\begin{array}{l}11.6 \pm \\
0.54^{\star}\end{array}$} & $15.3 \pm$ & $1.68 \pm$ & $3.51 \pm$ & $0.08 \pm$ & $0.15 \pm$ \\
\hline & & & $0.70 *$ & $0.08^{*}$ & $0.03^{*}$ & $0.01^{*}$ & $0.02^{\text {ns }}$ \\
\hline \multirow[t]{2}{*}{$t$ value } & 17.925 & 16.513 & 19.324 & 24.459 & 73.612 & 17.321 & -0.309 \\
\hline & $(p=0.003)$ & $\begin{array}{l}(p= \\
0.004)\end{array}$ & $\begin{array}{l}(p= \\
0.003)\end{array}$ & $\begin{array}{l}(p= \\
0.002)\end{array}$ & $\begin{array}{l}(p= \\
0.001)\end{array}$ & $\begin{array}{l}(p= \\
0.003)\end{array}$ & $\begin{array}{l}(p= \\
0.787)\end{array}$ \\
\hline \multicolumn{8}{|l|}{$S 2-4$} \\
\hline \multirow[t]{2}{*}{0} & $36.2 \pm$ & $19.3 \pm$ & $16.8 \pm$ & $2.50 \pm$ & $5.45 \pm$ & $0.08 \pm$ & $0.15 \pm$ \\
\hline & 1.43 & 0.76 & 0.67 & 0.04 & 0.13 & 0.01 & 0.00 \\
\hline \multirow[t]{2}{*}{100} & $20.3 \pm$ & $9.7 \pm$ & $10.7 \pm$ & $0.88 \pm$ & $1.89 \pm$ & $0.05 \pm$ & $0.12 \pm$ \\
\hline & $1.11 *$ & $0.54^{\star}$ & $0.57 *$ & $0.02^{\star}$ & $0.02^{*}$ & $0.01^{\mathrm{ns}}$ & $0.02^{n s}$ \\
\hline \multirow[t]{2}{*}{$t$ value } & 85.354 & 75.432 & 106.63 & 69.286 & 43.71 & 3.928 & 3.20 \\
\hline & $(p=0.001)$ & $\begin{array}{l}(p= \\
0.001)\end{array}$ & $\begin{array}{l}(p= \\
0.001)\end{array}$ & $\begin{array}{l}(p= \\
0.001)\end{array}$ & $\begin{array}{l}(p= \\
0.001)\end{array}$ & $\begin{array}{l}(p= \\
0.059)\end{array}$ & $\begin{array}{l}(p= \\
0.085)\end{array}$ \\
\hline
\end{tabular}

Data are mean of three replicates \pm standard deviation. Paired-Samples $T$-test $(0.05)$ were performed to compare the means of control and treatment, where $*$ significant and ns $=$ not significant.

Tolerance index

Tolerance index is a useful indicator to assess plant tolerance under metal stress. Indexes with high value signify higher tolerance and indexes with low value indicates lower tolerance or higher metal effect on plant (Shi and Cai 2009). The TI of seedling height, root length, shoot length, root dwt, shoot dwt, root fwt, and shoot fwt are shown in Fig. 1. Comparatively, the TI of seedling height of 16-024 significantly increased $(p<0.05)$ by $74.2 \%$ and S2-4 by $56.2 \%$ (Fig. 1.a). Also, the TI of root and shoot length of 16024 were $72.3 \%$ and $75.7 \%$, respectively. Those values were significantly higher than the root length ( $p<$ $0.05)$ and shoot length $(p<0.05)$ of $S 2-4$ which increased by $50.0 \%$ and $63.3 \%$, respectively. For root and 
shoot fwt 16-024 significantly increased by $52.9 \%$ and $40.8 \%$ respectively, compared to the root fwt and shoot fwt of S2-4 which were $35.2 \%$ and $34.7 \%$. The TI of root dwt of $16-024$ was higher (88.4 \%) but not significant $(p>0.05)$ compared to the root dwt of S2-4 (64.8\%). Similarly, the paired-samples $T$-test showed that there was no significant difference $(p>0.05)$ between the shoot dwt of $16-024(101.9 \%)$ and S2-4 (78.4\%). The higher tolerance of 16-024 under Cd stress is attributed to the higher values compared to S2-4. Recently, Palanivel et al. (2020) reported high TI of castor plant height (48-133\%), root dry wt. (25-360\%), and shoots dry wt. (18-328\%) when grown in five different types of copper mined soils and slag. The high TI value reported in their study compared to this present study may be associated with differences in metals and experimental conditions.

\section{Antioxidative enzymatic activities}

To combat Cd-induced oxidative damage, the plant's cell and organelle employ different antioxidant enzymes that help to control redox potential and tolerate oxidative stress. The production of antioxidant enzymes including SOD, CAT, among others play important roles to sequester, neutralize or detoxify Cd toxicity as a result of ROS production, thereby enhancing plant tolerance (Singh et al. 2016; Yeboah et al. 2020a). SOD is a metalloprotein that catalyzes the dismutation of two molecules of $\mathrm{O}^{2-}$ to $\mathrm{O}_{2}$ and $\mathrm{H}_{2} \mathrm{O}_{2}$ and helps protect cells against the toxic effects of $\mathrm{O}^{2-}$ produced in different cellular components (Bhaduri and Fulekar 2012) and CAT is a primary enzyme that regulates intracellular $\mathrm{H}_{2} \mathrm{O}_{2}$ level and catalyzes into $\mathrm{H}_{2} \mathrm{O}$ and divalent oxygen (Bhaduri and Fulekar 2012). The activities of SOD and CAT in the two castor accessions under $\mathrm{Cd}$ stress and their control groups are shown in Fig. $2 \mathrm{a}$ and $\mathrm{b}$. The activity of CAT significantly decreased $(p<0.001)$ in $16-024$ and increased $(p<0.05)$ in S2-4 compared to their control group. SOD and its activity significantly increased $(p<0.001)$ in the castor accessions under Cd treatment compared to their control groups. Increases in SOD and CAT activities were higher in S2-4 (1002.0 \pm 12.20 $\mathrm{U} / \mathrm{g}$ fw and $18.97 \pm 2.40 \mathrm{U} / \mathrm{g} \mathrm{fw})$ than $16-024(891.9 \pm 11.47 \mathrm{U} / \mathrm{g} \mathrm{fw}$ and $5.30 \pm 0.32 \mathrm{U} / \mathrm{g} \mathrm{fw})$. The higher SOD and CAT activities in S2-4 may be explained by the higher production of ROS in the leaves which was effectively converted to $\mathrm{H}_{2} \mathrm{O}_{2}$ by SOD and further converted to reusable by-products (water and oxygen molecules) by CAT. On the other hand, the decrease in CAT activity in 16-024 may be due to high reactive singlet molecular oxygen which inhibited the enzyme activity or disruption of protein synthesis caused by Cd toxicity (Ma et al. 2017). Another possible reason for the decrease in CAT may be due to the fact that the enhanced levels of SOD could not be sufficient to remove completely the generated ROS, which are capable of provoking the inhibition of CAT. The better coordination of enzymatic activities as witnessed by the maximum (S2-4) increases in SOD and CAT in the leaves of the S2-4 castor accession suggest effectiveness as the first line of defense in scavenging ROS and function in Cd detoxification in the leaves of castor plant. In agreement with our study, Zeng et al. (2 017) reported elevated levels of SOD activities (30.31-150.15\%) in the leaves of sugarcane among five different accessions which effectively eliminated oxidative stress caused by $\mathrm{Cd}$ toxicity. Existing studies have also reported enhanced SOD activities upon Cd stress (He et al. 2013; Li et al. 2013) except for Xu et al. (2014) who reported a decline SOD activity in maize seedlings which was attributed to inhibition caused by increasing $\mathrm{H}_{2} \mathrm{O}_{2}$ in the $\mathrm{Cd}$ treatment. Similarly, increase and decrease in CAT activity have been reported in rice (Yu et al. 2013), 
poplar (He et al. 2013), castor (Zhang et al. 2015), and sugarcane (Zeng et al. 2017) upon Cd exposure in the growth medium, which can be attributed to the different plant species and tissues, or concentrations and durations of metal exposure (Zhang et al. 2015). The different responses of antioxidant enzymes (SOD and CAT) in our study to Cd seem to be genotype-specific.

\section{Non-antioxidant enzymes}

GSH is a key component of non-protein thiols responsible for maintaining the cellular redox status. GSH acts as a chelating bio-ligand that neutralizes the oxidative stress caused by metal toxicity in plants. It also plays an important role by scavenging excess $\mathrm{H}_{2} \mathrm{O}_{2}$ and reacts with hydrogen radical, superoxide radical, and singlet oxygen (Cobbett 2000; Hall 2002). Increasing GSH levels is important for Cd detoxification since it is a precursor of PCs (components of non-protein thiols), which form complexes with $\mathrm{Cd}$ and sequester it into the vacuoles (Cobbett 2000). However, the present results revealed a concomitant decrease of GSH level in both accessions (Fig. 2c), with the effect being more severe in S2-4 $(3.54 \pm 0.24 \mu \mathrm{mol} / \mathrm{g})$ than $16-024(2.0 \pm 0.14 \mu \mathrm{mol} / \mathrm{g})$ which may be due to the increase of PC leading to higher resistance of plants to oxidative stress (Zhang et al. 2014). This finding conforms with that reported in castor (Zhang et al. 2014), Brassica chinensis L (Lou et al. 2017), and Zea mays L. (Singh et al. 2019), where decreased GSH levels under Cd stress were associated with the PC synthesis. Thus, it may be deduced that the depletion of GSH to reduce the toxicity of $\mathrm{Cd}$ could be a primary mechanism for plants to adapt to Cd stress.

\section{Lipid peroxidation}

MDA is the cytotoxic product of membrane lipids peroxidation, and it accumulates when plants are exposed to oxidative stress. Therefore, the MDA content is mostly considered as a basic biomarker of lipid peroxidation and the stress level (Guo et al. 2014). In this study, we found that accumulation of MDA decreased $(p>0.05)$ by $0.44 \pm 0.15 \mathrm{nmol} / \mathrm{g}$ in accession $16-024$ and significantly increased $(p<0.05)$ by $2.67 \pm 0.07 \mathrm{nmol} / \mathrm{g}$ in accession S2-4, upon exposure to Cd as compared to their controls (Fig. $2 \mathrm{~d}$ ). This result is consistent with that reported in two different rice accessions, where MDA content decreased in Cd-tolerant cultivar 'Jaya' and increased in Cd-sensitive cultivar 'Ratna' when treated with Cd (100 and $500 \mu \mathrm{M}$ ) stress for 20 days in the growth medium (Shah et al. 2001). Bauddh and Singh (2016) also reported higher MDA contents in the leaves ( 4.53 fold ) of Brassica juncea L. compared to the leaves (2.8 fold) of castor when subjected to $C d$ treatment. MDA levels reflect the degree of cell membrane damage caused by oxidative stress. Hence, the increased MDA content of Cd-sensitive accession S2-4 indirectly explains the oxidative stress induced by $\mathrm{Cd}$ stress compared with that of 16-024. The decreased MDA content in 16-024 may be explained by the quick removal of ROS by antioxidant enzymes particularly, SOD and CAT which acts as the first line of defense against free radicals. Higher SOD activities in different cellular compartments under $\mathrm{Cd}$ stress signifies higher $\mathrm{O}^{2-}$, capable of causing oxidative damage (Zhang et al. 2015). Therefore, the growth and decrease in MDA content in the leaves of 16-024 may be attributed to the low accumulation of free radicals which was effectively removed by SOD. This result may explain the higher tolerance to Cd stress in 16-024 compared to S2-4. 


\section{Conclusion}

This study was undertaken to comparatively evaluate two contrasting wild castor accessions to $\mathrm{Cd}$ stress. From this study, it can be concluded that the growth and tolerance of castor under Cd toxicity varies between accessions. The addition of $\mathrm{Cd}$ in the growth medium inhibited the growth and biomass of castor and the level of tolerance to $\mathrm{Cd}$ toxicity varied between the accessions. Accession 16-024 exhibited higher tolerance to $\mathrm{Cd}$ toxicity which was observed in the increase in higher $\mathrm{Tl}$, decrease in MDA content, and GSH levels compared to S2-4. Although the expression of the antioxidant enzymes in 16024 were low compared to S2-4, it may be that Cd stress did not induce much ROS production as observed by the decrease in MDA content and hence the antioxidant enzymes did not have much ROS to scavenge. This renders $16-024$ as a more tolerant accession and better suited for further screening and utilization in genetic breeding improvement programs aimed at Cd tolerance over S2-4. However, it is recommended that future studies should include multi-omics strategies (transcriptomics and metabolomics) to unravel transcripts and metabolites regulation in these two accessions to boost our understanding.

\section{Declarations}

\section{Ethics approval and consent to participate}

Not applicable

\section{Consent to publish}

Not applicable

\section{Availability of data and materials}

The datasets used and/or analysed during the current study are available from the corresponding author on reasonable request.

Competing interests: The authors declare that they have no conflicts of interest to report regarding the present study.

\section{Funding}

This study was funded by National natural science foundation of China, (31271759); Guangdong provincial science and technology projects (2013b060400024, 2014a020208116, and 2016a020208015) (China); Project of enhancing school with innovation of Guangdong ocean university, GDOU2013050206 (China).

\section{Authors' contributions}


AY, LJ, SG, LH, HAD: Investigation, Formal analysis. KG and JP: Investigation, Resources. AY, LJ, KGAB, and JP: Revision, Review. XY: Conceptualization, Supervision.

\section{Acknowledgments}

We are thankful to Dr. Adzigbli Linda, Dr. Benjamin Kariakri, and Asiamah Collins, and all anonymous reviewers for making this manuscript a better one.

\section{References}

1. Aebi H (1984) Aebi, Hugo. ed." Catalase in vitro Methods Enzymol 105:121-126

2. Anjani K (2014) A re-evaluation of castor (Ricinus communis L.) as a crop plant CAB Reviews 9:1-21

3. Bauddh K, Kumar A, Srivastava S, Singh RP et al. (2016) A study on the effect of cadmium on the antioxidative defense system and alteration in different functional groups in castor bean and Indian mustard Arch Agron Soil Sci 62:877-891

4. Bauddh K, Singh RP (2012) Cadmium tolerance and its phytoremediation by two oil yielding plants Ricinus communis (L.) and Brassica juncea (L.) from the contaminated soil Int $\mathrm{J}$ Phytoremediat 14:772-785

5. Beauchamp C, Fridovich I (1971) Superoxide dismutase: improved assays and an assay applicable to acrylamide gels Anal Biochem 44:276-287

6. Bhaduri AM, Fulekar M (2012) Antioxidant enzyme responses of plants to heavy metal stress Rev Environ Sci Bio 11:55-69

7. Cobbett CS (2000) Phytochelatins and their roles in heavy metal detoxification Plant physiology 123:825-832

8. Dandan L, Dongmei Z, Peng W, Nanyan W et al. (2011) Subcellular Cd distribution and its correlation with antioxidant enzymatic activities in wheat (Triticum aestivum) roots Ecotoxicol Environ Saf 74:874-881

9. de Souza Costa ET, Guilherme LRG, de Melo ÉEC, Ribeiro BT et al. (2012) Assessing the tolerance of castor bean to $\mathrm{Cd}$ and $\mathrm{Pb}$ for phytoremediation purposes Biol Trace Elem Res 145:93-100

10. Dhindsa RS, Plumb-Dhindsa P, Thorpe TA (1981) Leaf senescence: correlated with increased levels of membrane permeability and lipid peroxidation, and decreased levels of superoxide dismutase and catalase J Exp Bot 32:93-101

11. Eyer P, Podhradský D (1986) Evaluation of the micromethod for determination of glutathione using enzymatic cycling and Ellman's reagent Anal Biochem 153:57-66

12. Gill SS, Khan NA, Anjum NA, Tuteja N (2011) Amelioration of cadmium stress in crop plants by nutrients management: morphological, physiological and biochemical aspects Plant Stress 5:1-23

13. Guo Q, Meng L, Mao P, Tian X (2014) An assessment of Agropyron cristatum tolerance to cadmium contaminated soil Biol Plantarum 58:174-178 
14. Guo Z, Gao Y, Cao X, Jiang W et al. (2019) Phytoremediation of Cd and Pb interactive polluted soils by switchgrass (Panicum virgatum L.) Int J Phytoremediat 21:1486-1496

15. Hall J (2002) Cellular mechanisms for heavy metal detoxification and tolerance J Exp Bot 53:1-11

16. Hazama K, Nagata S, Fujimori T, Yanagisawa S et al. (2015) Concentrations of metals and potential metal-binding compounds and speciation of $\mathrm{Cd}, \mathrm{Zn}$ and $\mathrm{Cu}$ in phloem and xylem saps from castor bean plants (Ricinus communis) treated with four levels of cadmium Physiol Plant 154:243-255

17. He C, Zhao Y, Wang F, Oh K et al. (2020) Phytoremediation of soil heavy metals (Cd and Zn) by castor seedlings: Tolerance, accumulation and subcellular distribution Chemosphere 252:126471

18. He J, Ma C, Ma Y, Li H et al. (2013) Cadmium tolerance in six poplar species Environ Sci Pollut R 20:163-174

19. Hoagland DR, Arnon DI (1950) The water-culture method for growing plants without soil Circular California agricultural experiment station 347

20. Huang H, Yu N, Wang L, Gupta D et al. (2011) The phytoremediation potential of bioenergy crop Ricinus communis for DDTs and cadmium co-contaminated soil Bioresour Technol 102:1103411038

21. Kang W, Bao J, Zheng J, Hu H et al. (2015) Distribution and chemical forms of copper in the root cells of castor seedlings and their tolerance to copper phytotoxicity in hydroponic culture Environ Sci Pollut R 22

22. Kiran BR, Prasad MNV (2017) Responses of Ricinus communis L.(castor bean, phytoremediation crop) seedlings to lead $(\mathrm{Pb})$ toxicity in hydroponics Selcuk Journal of Agriculture and Food Sciences 31:73-80

23. Knörzer OC, Burner J, Boger P (1996) Alterations in the antioxidative system of suspension-cultured soybean cells (Glycine max) induced by oxidative stress Physiol Plant 97:388-396

24. Li F-t, Qi J-m, Zhang G-y, Lin L-h et al. (2013) Effect of cadmium stress on the growth, antioxidative enzymes and lipid peroxidation in two kenaf (Hibiscus cannabinus L.) plant seedlings $\mathrm{J}$ Integr Agr 12:610-620

25. Lou L, Kang J, Pang H, Li Q et al. (2017) Sulfur Protects Pakchoi (Brassica chinensis L.) Seedlings against Cadmium Stress by Regulating Ascorbate-Glutathione Metabolism Int J Mol Sci 18:1628

26. Ma X, Deng D, Chen W (2017) Inhibitors and Activators of SOD, GSH-Px, and CAT Enzyme inhibitors and activators 29:207

27. Pal R, Banerjee A, Kundu R (2013) Responses of castor bean (Ricinus communis L.) to lead stress Proceedings of the National Academy of Sciences, India Section B: Biological Sciences 83:643-650

28. Palanivel TM, Pracejus B, Victor R (2020) Phytoremediation potential of castor (Ricinus communis L.) in the soils of the abandoned copper mine in Northern Oman: implications for arid regions Environ Sci Pollut R 27:17359-17369

29. Prasad MNV (2017) Responses of Ricinus communis L.(castor bean, phytoremediation crop) seedlings to lead $(\mathrm{Pb})$ toxicity in hydroponics Selcuk Journal of Agriculture and Food Sciences 31:73- 
80

30. Shah K, Kumar RG, Verma S, Dubey R (2001) Effect of cadmium on lipid peroxidation, superoxide anion generation and activities of antioxidant enzymes in growing rice seedlings Plant Science 161:1135-1144

31. Shahid M, Dumat C, Khalid S, Niazi NK et al. (2016) Cadmium bioavailability, uptake, toxicity and detoxification in soil-plant system. In: Rev Environ Contam T Volume 241. Springer, pp 73-137

32. Sharma H, Rawal N, Mathew BB (2015) The characteristics, toxicity and effects of cadmium Int J Nanotechnol 3:1-9

33. Shi G, Cai Q (2009) Cadmium tolerance and accumulation in eight potential energy crops Biotechnol Adv 27:555-561

34. Singh S, Parihar P, Singh R, Singh VP et al. (2016) Heavy metal tolerance in plants: role of transcriptomics, proteomics, metabolomics, and ionomics Frontiers in plant science 6:1143

35. Singh S, Singh VP, Prasad SM, Sharma S et al. (2019) Interactive Effect of Silicon (Si) and Salicylic Acid (SA) in Maize Seedlings and Their Mechanisms of Cadmium (Cd) Toxicity Alleviation J Plant Growth Regul 38:1587-1597

36. Tinkov AA, Filippini T, Ajsuvakova OP, Skalnaya MG et al. (2018) Cadmium and atherosclerosis: A review of toxicological mechanisms and a meta-analysis of epidemiologic studies Environ Res 162:240-260

37. Wang S, Zhao Y, Guo J, Zhou L (2016) Effects of Cd, Cu and Zn on Ricinus communis L. Growth in single element or co-contaminated soils: Pot experiments Ecol Eng 90:347-351

38. Wu S, Shen C, Yang Z, Lin B et al. (2016) Tolerance of Ricinus communis L. to Cd and screening of high $\mathrm{Cd}$ accumulation varieties for remediation of $\mathrm{Cd}$ contaminated soils Int $\mathrm{J}$ Phytoremediat 18:1148-1154

39. Xu X, Liu C, Zhao X, Li R et al. (2014) Involvement of an antioxidant defense system in the adaptive response to cadmium in maize seedlings (Zea mays L.) Bull Environ Contam Toxicol 93:618-624

40. Yang W, Wu F, Ding Z, Zhang X et al. (2018) Cadmium accumulation and tolerance in seven ornamental willow genotypes Bull Environ Contam Toxicol 101:644-650

41. Ye W, Guo G, Wu F, Fan T et al. (2018) Absorption, translocation, and detoxification of Cd in two different castor bean (Ricinus communis L.) cultivars Environ Sci Pollut R 25:28899-28906 doi:10.1007/s11356-018-2915

42. Yeboah A, Lu J, Gu S, Shi Y et al. (2020a) The utilization of Ricinus communis $L$ in the phytomanagement of heavy-metal contaminated soil Environ Rev 28:466-477

43. Yeboah A, Lu J, Yang T, Shi Y et al. (2020b) Assessment of Castor Plant (Ricinus communis L.) Tolerance to Heavy Metal Stress-A Review Phyton-Int J Exp Bot 89:453-472

44. Yeboah A, Ying S, Lu J, Xie Y et al. (2020c) Castor oil (Ricinus communis): a review on the chemical composition and physicochemical properties Food Science and Technology 
45. Yu F, Liu K, Li M, Zhou Z et al. (2013) Effects of cadmium on enzymatic and non-enzymatic antioxidative defences of rice (Oryza sativa L.) Int J Phytoremediat 15:513-521

46. Zacchini M, Pietrini F, Scarascia Mugnozza G, lori V et al. (2009) Metal Tolerance, Accumulation and Translocation in Poplar and Willow Clones Treated with Cadmium in Hydroponics Water Air Soil Poll 197:23-34

47. Zeng Q, Ling Q, Hu F, Wu J et al. (2017) Genotypic differences in growth and antioxidant enzyme activities under cadmium stress in sugarcane Bull Environ Contam Toxicol 99:607-613

48. Zhang H, Guo Q, Yang J, Chen T et al. (2014) Cadmium accumulation and tolerance of two castor cultivars in relation to antioxidant systems J Environ Sci 26:2048-2055

49. Zhang H, Guo Q, Yang J, Shen J et al. (2015) Subcellular cadmium distribution and antioxidant enzymatic activities in the leaves of two castor (Ricinus communis L.) cultivars exhibit differences in Cd accumulation Ecotoxicol Environ Saf 120:184-192

\section{Figures}

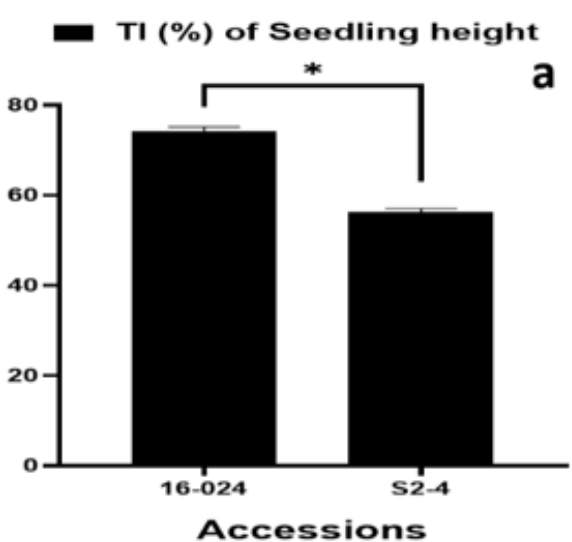

- TI (\%) of Root fwt.

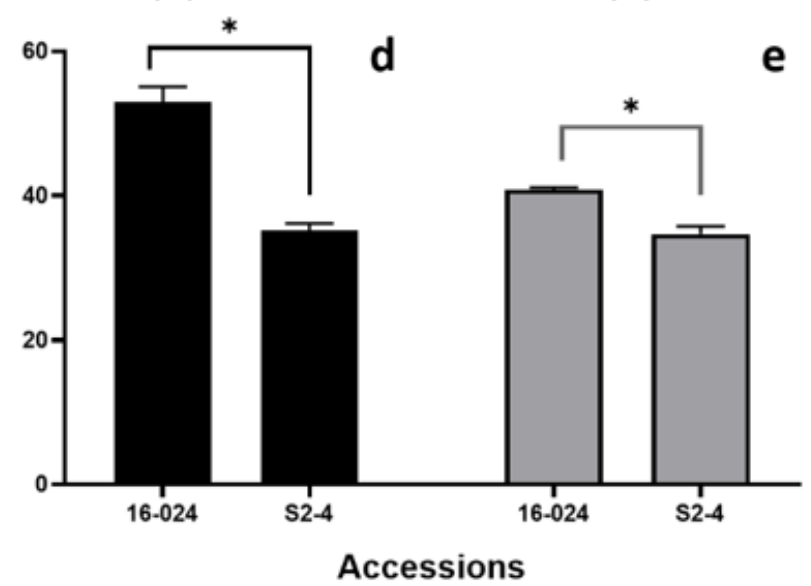

TI (\%) of Root length
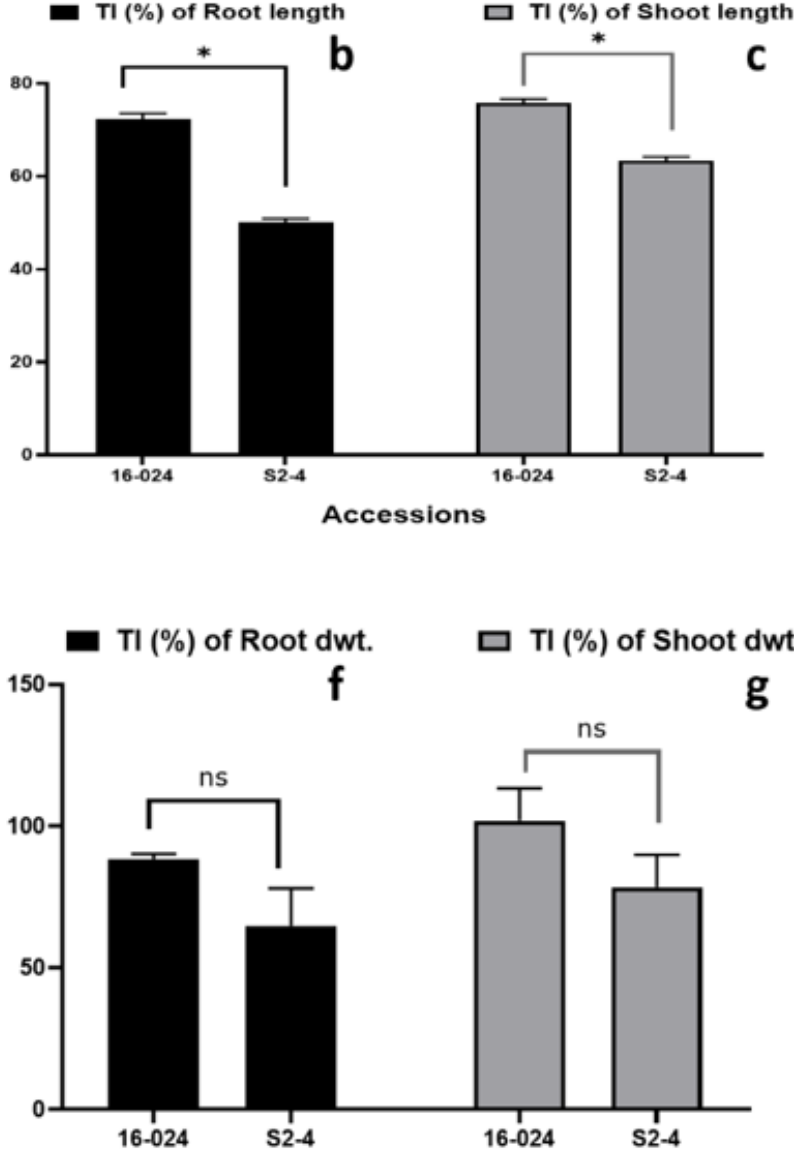

Accessions

Figure 1 
Tolerance index ( $\mathrm{TI} \%$ ) of seedling height (a), root length (b), shoot length (c), root fwt. (d), shoot fwt (e), root dwt. (f), and shoot dry wt. (g) of castor in Cd stress(Data are mean of three replicate and error bar represents standard deviation of the three replications). Paired-Samples T-test (0.05) were performed to compare between the two wild castor accessions, where * = significant and ns = not significant.

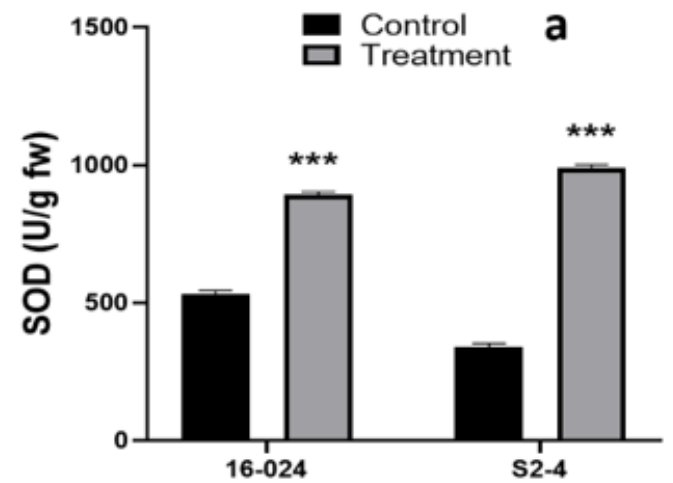

Accessions

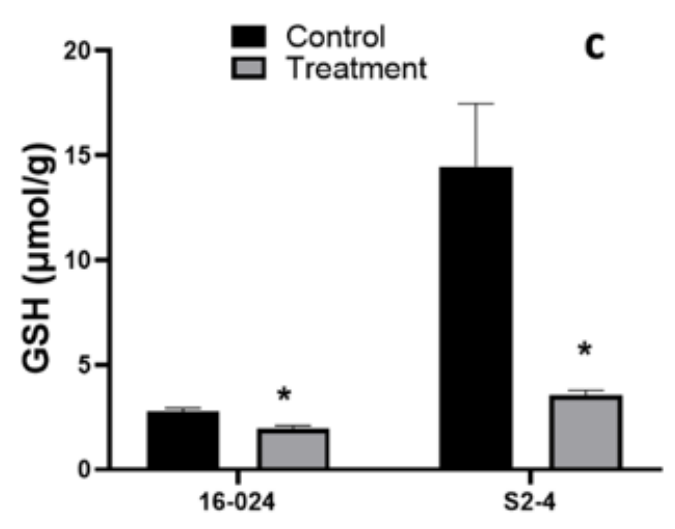

Accessions

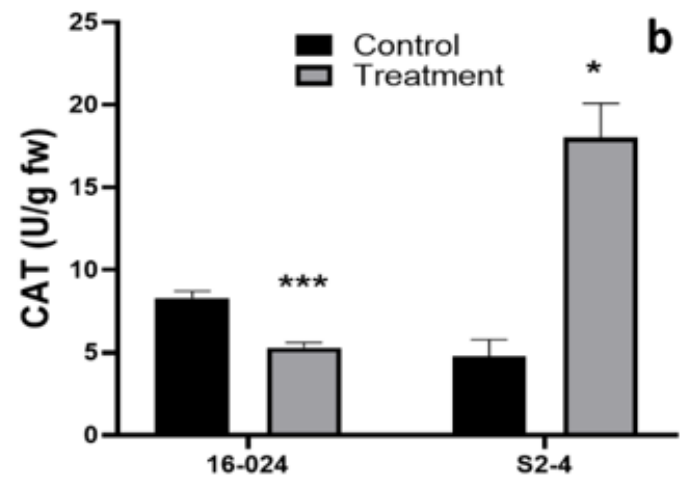

Accessions

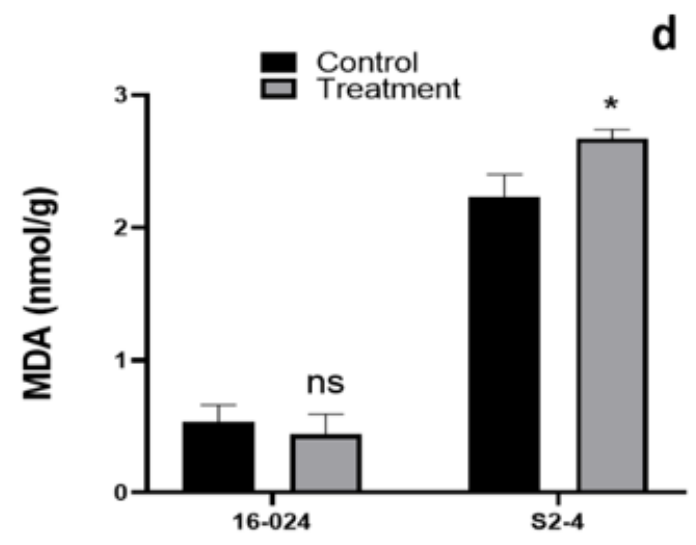

Accessions

\section{Figure 2}

The response of superoxide dismutase (SOD, a), catalase (CAT, b) glutathione (GSH, c), and malondialdehyde (MDA, $d$ ) in leaves of two castor accessions grown under $\mathrm{Cd}$ stress and without stress for 5 days Data are mean of three replicate and error bar represents standard deviation of the three replications. Significant differences from the control are indicated as * $p<0.05$, $* \star * p<0.001$ based on paired samples T-test (0.05). 